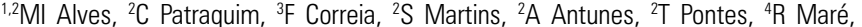
${ }^{2.5 \mathrm{H}}$ Antunes. 'Serviço de Pediatria, Centro Hospitalar São João, Porto; ' $U n i d a d e$ Adolescentes, Serviço de Pediatria, Hospital de Braga, Braga; ${ }^{3}$ Serviço de Pediatria, Centro Hospitalar Alto Ave, Guimarães; ${ }^{4}$ Serviço de Neurologia, Hospital de Braga, Braga; ${ }^{5}$ nstituto de Ciências da Vida e da Saúde (ICVS), Escola de Ciências da Saúde da Universidade do Minho, Laboratório Associado ICVS/3B's, Braga/Guimarães, Portugal

Background The segmental spinal cord syndrome is defined clinically as a neurological injury (incomplete or complete) sensory, motor and autonomic.

Results 13 year old female, previously healthy with a sudden onset of severe pain in the inferior limbs, with loss of strength and sensitivity. No history of fever, recent trauma, infection, vaccination or similar episode. The physical examination revealed areflexic flaccid paraplegia, abolished postural sensitivities, painful hypoesthesia with sensitive level at T8, bilateral indifferent cutaneous plantar reflex response and vesical globe.

A brain and spinal cord magnetic ressonance imaging (MRI) study showed a discreet hyperintensity of the conus, and cerebrospinal fluid analysis was normal. She was hospitalized admitting a possible diagnosis of transverse myelitis and medicated with methylprednisolone intravenously. Due to the absence of clinical improvement, at day five MRI was repeated showing extensive hyperintensity of the conus with restricted diffusion, which extended to the level of T10, diagnostic hypothesis of acute transverse myelitis or acute ischemic injury was made. An etiological study was conducted presenting heterozygosity for Factor V Leiden. On day 32, after submission to physiotherapy, with slight improvement of proximal weakness in the lower limbs, a new MRI showed spinal cord atrophy.

Conclusions In this case, the main challenge is to establish the diagnosis and its etiology. Clinically, transverse myelitis is the most probable diagnosis although by imaging, one cannot exclude spinal cord infarction. Regardless of this issue, the overall prognosis, conditioned by severe initial dysfunction and no recovery in the first 24 hours, is unfavorable.

\section{SELF-ASSESSMENT OF APPEARANCE AND USING OF SLIMIMING SUPPLEMENTS AND ERGOGENIC AIDS AMONG POLISH STUDENTS FROM JUNIOR HIGH SCHOOLS}

doi:10.1136/archdischild-2012-302724.0457

'E Kolarzyk, ${ }^{2} \mathrm{~J} J$ Jośko, ${ }^{2} \mathrm{~J}$ Kasperczyk, 'A Ostachowska-Gąsior. 'Department of Hygiene and Dietetics, Jagiellonian University, Medical College, Krakow; ${ }^{2}$ Department of Environmental Medicine and Epidemiology, Medical University of Silesia, Zabrze, Poland

Dynamic physical and psychological changes connected with adolescence are associated with focusing on appearance. The difference between the imagine figure and real appearance can become a source of frustration and dissatisfaction.

The aim Assessment of body weight acceptance and different actions aiming at appearance improvement among Polish students from junior high schools.

Methods The examinations included 986 students from junior high schools (551girls and 435 boys) at the mean age 13 years and BMI 19.28 \pm 2.85 (girls) and 19.90 \pm 4.51 (boys). An anonymous standardized questionnaire concerning nutritional behaviors was used. Results Dissatisfaction with body mass and general appearance was declared by $31.4 \%$ boys and $40.6 \%$ girls. The majority of these girls used different weight-loss diets (reduction, low-carbohydrate, protein, yoghurt and fruit diets) and nonconventional diets such $\mathrm{dr}$ Atkins' and South Beach. Supplements which stimulate fat tissue burn, metabolic process and thermogenesis and such products as Alli, Bio CLA, Linea and Therm Line II were the most popular. The boys declared taking the ergogenic aids (vitamin and mineral preparations) and supplementation with protein or carbohydrate. The reduction of body mass was the goal for $8 \%$ of boys and they also decided to start a weight-loss diet.
Conclusions Low level of self-assessment and lack of appearance acceptance may lead to disturbances with physical and mental health.

In Poland dietary supplements and nutrients are sold without prescription even in filling stations and supermarkets and we afraid that young people will abuse them to create their figure according to their imagine.

\section{THE WAY OF NUTRITION OF POLISH JUNIOR HIGH SCHOOLS PUPILS}

doi:10.1136/archdischild-2012-302724.0458

'E Kolarzyk, ${ }^{2} \mathrm{~J}$ Jośko, 'A Ostachowska-Gąsior, ${ }^{3} \mathrm{~J}$ Kasperczyk. 'Department of Hygiene and Dietetics, Jagiellonian University, Medical College, Krakow; ${ }^{2}$ Department of Environmental Medicine and Epidemiology, Medical University of Silesia, Zabrze; ${ }^{3}$ Department of Environmental Medicine and Epidemiology, Medical University of Silesia, Krakow, Poland

The proper nutrition is important at every period of human life but particularly in adolescence.

The aim Estimation of the frequency of regular consumption of particular meals and the characterization of nutritional habits of junior high schools pupils.

Methods The examinations included 986 students from junior high schools ( 435 boys and 551 girls) at the mean age 13 years and BMI $19.28 \pm 2.85 \mathrm{~kg} / \mathrm{m}^{2}$ (girls) and $19.90 \pm 4.51 \mathrm{~kg} / \mathrm{m}^{2}$ (boys). An anonymous standardized questionnaire concerning nutritional behaviors was used in the study.

Results Breakfast was eaten regularly by $71.7 \%$ (67.6\% girls and $76.8 \%$ boys); second breakfast: $36.7 \%$ (38.1\% girls and $34.5 \%$ boys); lunch: 87.8 (84.9\% girls and $91.0 \%$ boys); desert $22.1 \%$ (21.7\% girls and $22.3 \%$ boys) ; supper: $73.9 \%$ (66.5\% girls and $82.8 \%$ boys). Basic meals were more often omitted by girls than by boys. $33.6 \%$ of girls and $29.0 \%$ of boys eat something among the main meals. It should be pointed out that $25 \%$ of these young people eat their meals alone. Nearly half of the examined group eat chips, cakes, sweets like Snikers, Mars etc. and drink cola, sprite, pepsi. When pupils were asked about the frequency of fast food consumption $2 / 3$ of them answered "sometimes". The answer "never" was chosen by $19.1 \%$ of girls and $18.2 \%$ of boys.

Conclusion The examined group of pupils showed many nutritional mistakes and the way of nutrition becomes far from traditional Polish pattern and becomes similar to nutritional model present in USA and West Europe.

\section{FAMILY FACTORS MODIFYING THE EATING DISORDERS OF YOUNG PEOPLE IN POLAND}

doi:10.1136/archdischild-2012-302724.0459

${ }^{1} \mathrm{~J}$ Josko, ${ }^{2} \mathrm{E}$ Kolarzyk, ' J Kasperczyk, 'U Marcinkowska, ' $\mathrm{K}$ Lau, ${ }^{1} \mathrm{M}$ Tyrpień, ${ }^{3} \mathrm{~K}$ Helewski. ${ }^{1}$ Chair and Departement of Medicine and Environmental Epidemiology, Medical University of Silesia, Zabrze; ${ }^{2}$ Department of Hygiene and Dietetics, Jagiellonian University, Medical College, Krakow; ${ }^{3}$ Department of Histology and Embryology, Medical University of Silesia, Zabrze, Poland

Background and Aims The independent predictors of eating disorders model, characteristic of the families whose children suffer from anorexia is to prefer to be "good parents" than marriage ties and close family relationship. In those families the influence of a father on the premorbid and the accompanying disease personality of children is underestimated. The role of fathers is especially important during daughters' adolescence, who need then their full acceptance. The aim of the study: is there a relationship between age and education of parents and behaviors that may precede the incidence of anorexia.

Methods 1050 middle school students (13.8 \pm 0.98 year old) from Poland, have been examined using anonymous standardized 